\title{
False blister beetles of the genus Oedemera in Scotland
}

\author{
B. Philp \\ 7 Glebe Crescent, Ochiltree KA18 2QP \\ E-mail: brucephilp47@gmail.com
}

\begin{abstract}
The status and distribution of the Scottish false blister beetles (Oedemeridae) are summarised with particular reference to the genus Oedemera. Within this genus only three species have been reliably recorded in Scotland. Of the two widespread species virtually all the records are post-1990. One species - O. virescens - appears to be very common in the south of Scotland whereas the other species - O. lurida - is recorded mainly north of the central belt. While identification problems may partly account for these differences, they do not appear to provide a complete explanation with other unknown factors influencing their distribution.
\end{abstract}

\section{INTRODUCTION}

The Oedemeridae is a relatively small family of softbodied, elongate beetles that could be mistaken for soldier beetles (Cantharidae) or longhorn beetles (Cerambycidae). In total there are ten species in Britain, although only six of these occur in Scotland including Chrysanthia geniculata, which is restricted to a single site on Deeside (Duff, 2020) and Nacerdes melanura, an introduced species that is found in waterlogged wood, usually around the coast. There is a single record of $N$. melanura in Scotland according to the NBN Atlas (National Biodiversity Network, 2021a), although Richard Lyszkowski (pers. comm.) regards it as not uncommon on the east coast, and the Glasgow Museums Biological Records Centre has two records from Glasgow (R.B. Weddle, pers. comm.).

The remaining four species belong to the genus Oedemera. Three of these are superficially similar leading to difficulties with identification and consequently this has led to confusion over their distribution. The identification of the four species is well described in Duff (2020) and will not be repeated here; instead what is known of their current distribution in Scotland will be reviewed.

\section{THE OEDEMERA SPECIES}

As adults of the four species feed on flowers, they can be quite conspicuous and are often numerous. More than one species can be present at the same site and since three are green in colouration it can be challenging to separate them.

\section{Oedemera femoralis}

The largest species is $O$. femoralis, which is brown rather than green and measures $13-20 \mathrm{~mm}$ in length (this and subsequent dimensions from Duff, 2020). However, it has a distinctive elongate shape with slim elytra which taper towards the rear and characterise the genus (Fig. 1). Unusually for a British beetle it is mainly nocturnal with an apparent preference for ivy (Hedera helix) (Duff, 2020). A recent summary of the status of several families of British beetles classifies $O$. femoralis as Nationally Scarce, meaning that it has been recorded from just 16-100 hectads (10x10 km squares) in Britain since 1990 (Lane et al., 2019).

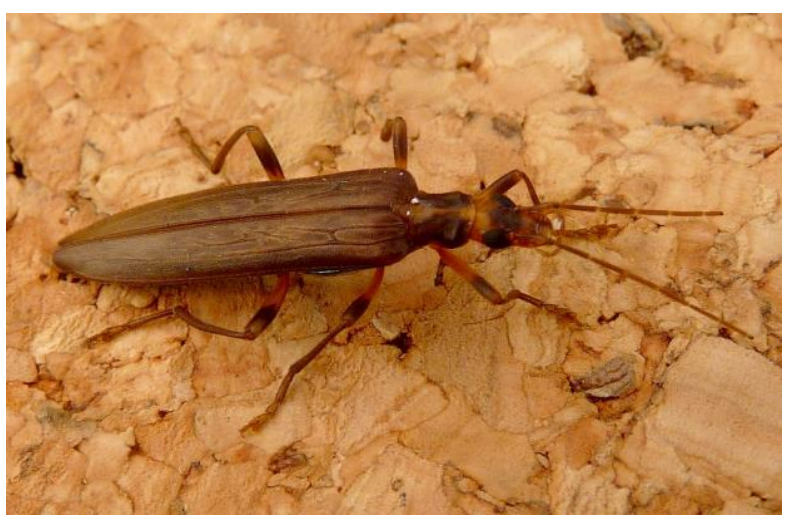

Fig. 1. Oedemera femoralis. (Photo: @gailhampshire)

In Scotland its status is uncertain. The review of the family by Alexander et al. (2014) includes it as Scottish while the NBN Atlas has no Scottish records. However, Crowson (1964) found larvae in thick ivy stems at Portencross in Ayrshire, while it has also been reported from Abbey Craig near Stirling (Waterston, 1935; Cathrine et al., 2020; Richard Lyszkowski, pers. comm.), in these cases associated once again with ivy. A further record was reported in 2012, although the exact location is not known (Sullivan, 2012).

The scattered records noted above show no obvious pattern and it seems possible that it may be more widely distributed although probably scarce. There is certainly no shortage of ivy and so perhaps its nocturnal habits have kept it from wider notice. Beating ivy at night may well produce new records.

\section{Oedemera nobilis}

Known as the swollen-thighed beetle, this is a common species in England and Wales from the Midlands southwards, with scattered records in northern England (National Biodiversity Network, 2021b). The grossly 
swollen hind femora make the male unmistakable, but the female is more similar to the following two species, although generally it is a brighter green. O. nobilis of both sexes are distinctive in having relatively narrow elytra that do not meet in the middle towards the rear (Fig. 2). While their length $(6-11 \mathrm{~mm})$ overlaps with that of $O$. virescens and $O$. lurida (Vásquez, 2002; Duff, 2020), their brighter green colour should make even the females distinctive.

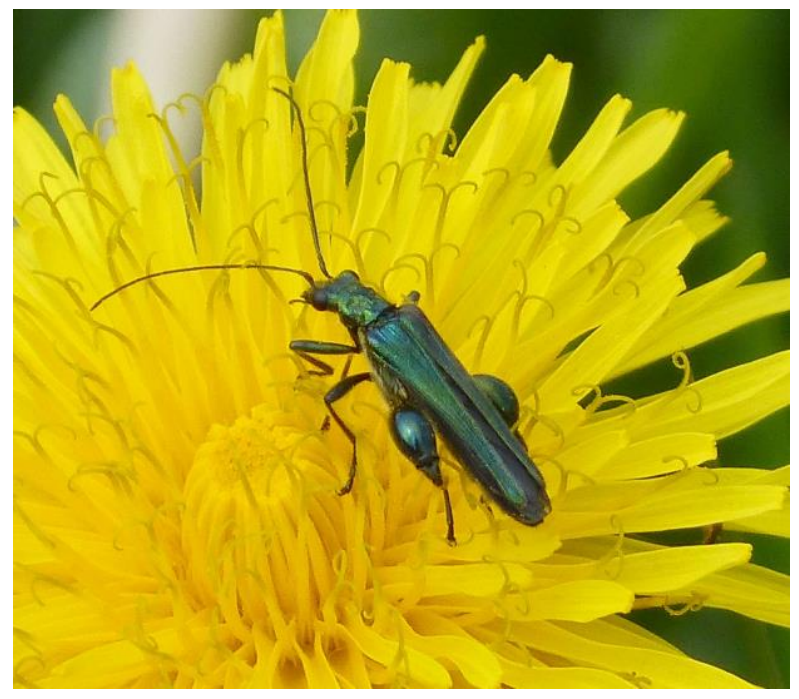

Fig. 2. Oedemera nobilis (male). (Photo: @gailhampshire)

A review of the status of the Oedemeridae (Alexander $e t$ al., 2014) gives no records for Scotland, but two are noted in the NBN Atlas. One of these is an error, as acknowledged by the recorder and the other is unverified. There are also four records in the Biological Records Centre's iRecord but, from the accompanying photographs, these are, with one exception, Oedemera virescens or lurida. The exception is a male but, while the grid reference suggests a site near Leadhills, Lanarkshire, the accompanying written description states that it is in Nottinghamshire. Because of the similarity between the three species, records for $O$. nobilis should be accepted only where a photograph exists or where the recorder is experienced with the species. The generally southern distribution suggests that this species is unlikely to be found in Scotland.

\section{Oedemera virescens}

The features that characterise this species can be quite subtle. It has a length of $6.5-11 \mathrm{~mm}$ and is frequently described as being a dull, sage-green in colour. The hind femora of males are swollen (Fig. 3), although not nearly as much as those of $O$. nobilis. The females have thin hind femora, as in O. lurida, and can be difficult to distinguish from that species. They can, however, be separated from $O$. lurida by the shape of the last ventral abdominal segment. This can be difficult to see in these soft-bodied insects and needs to be examined carefully.

This is the least common species of the genus in Britain with Lane et al. (2019) giving it Nationally Rare status signifying that it has been recorded in fewer than 15 hectads in the U.K. since 1990. Indeed, in a previous

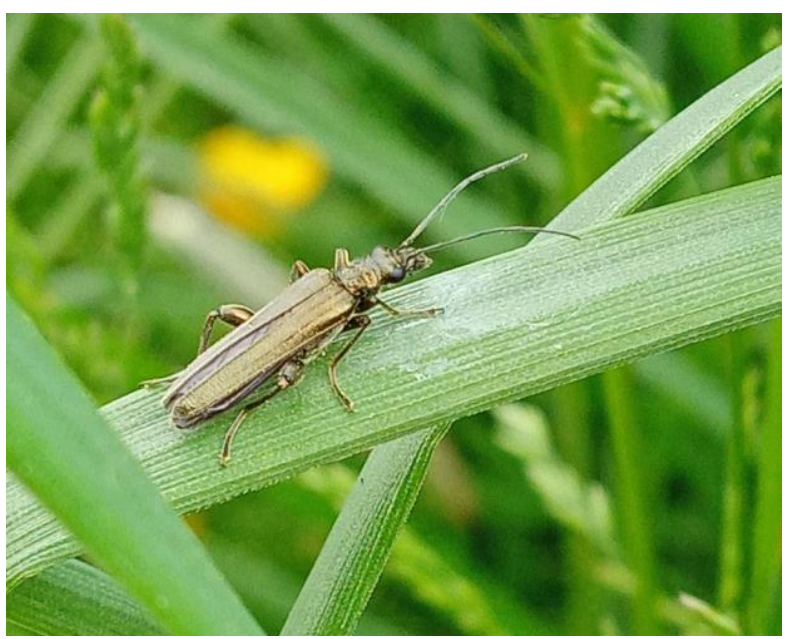

Fig. 3. Oedemera virescens. (Photo: B. Philp)

review of the status of British Coleoptera, Hyman \& Parsons (1992) regarded it as a Vulnerable Red Data Book species, as they stated that it had been recorded in only three hectads between 1970 and 1990, all of them in north-east Yorkshire. The first Scottish record was from the Forest of Ae in Dumfriesshire in 1992/93 (Morris, 1997) followed by a few scattered records until an upsurge from around 2010. After this, and partly as result of targeted appeals for records (Philp, 2014; and unpublished), many more records were received. With now well in excess of 200 records from 72 hectads, all in the south of Scotland (Fig. 4), it would appear that the species can no longer be regarded as Nationally Rare.

The apparent significant increase in the range of this species cannot be attributed solely to the targeted recording mentioned above. Feeding in large numbers on its favourite buttercup (Ranunculus spp.) flowers between May and July, it is a very conspicuous insect and it seems unlikely that it was overlooked by earlier coleopterists. It would appear that there has been an expansion in the species' range and, although there might be a temptation to link this to the effects of climate change, there is no direct evidence to support this idea.

\section{Oedemera lurida}

With a length of $5-8 \mathrm{~mm}$, this is the smallest of the Oedemera species, although there is considerable overlap (Vásquez, 2002; Duff, 2020). It is much the same sage green colour as $O$. virescens with both sexes having thin hind femora (Fig. 5). Once again, the shape of last ventral abdominal segment of the females is distinctive but difficult to confirm without magnification.

Surprisingly, Alexander et al. (2014) do not include Scotland in this species' range, although it was recorded from the Pitlochry area in Perthshire in 1884 (Beaumont, 1884). Beaumont gives the specific name as Oedemera livida, although Fergusson (1914) in listing recent additions to Scotland's beetle fauna called it $O$. lurida. The next records are from 1991 (Magnus Sinclair, pers. comm.) with another two up to 2000 (National Biodiversity Network, 2021c), all of them within mid- 

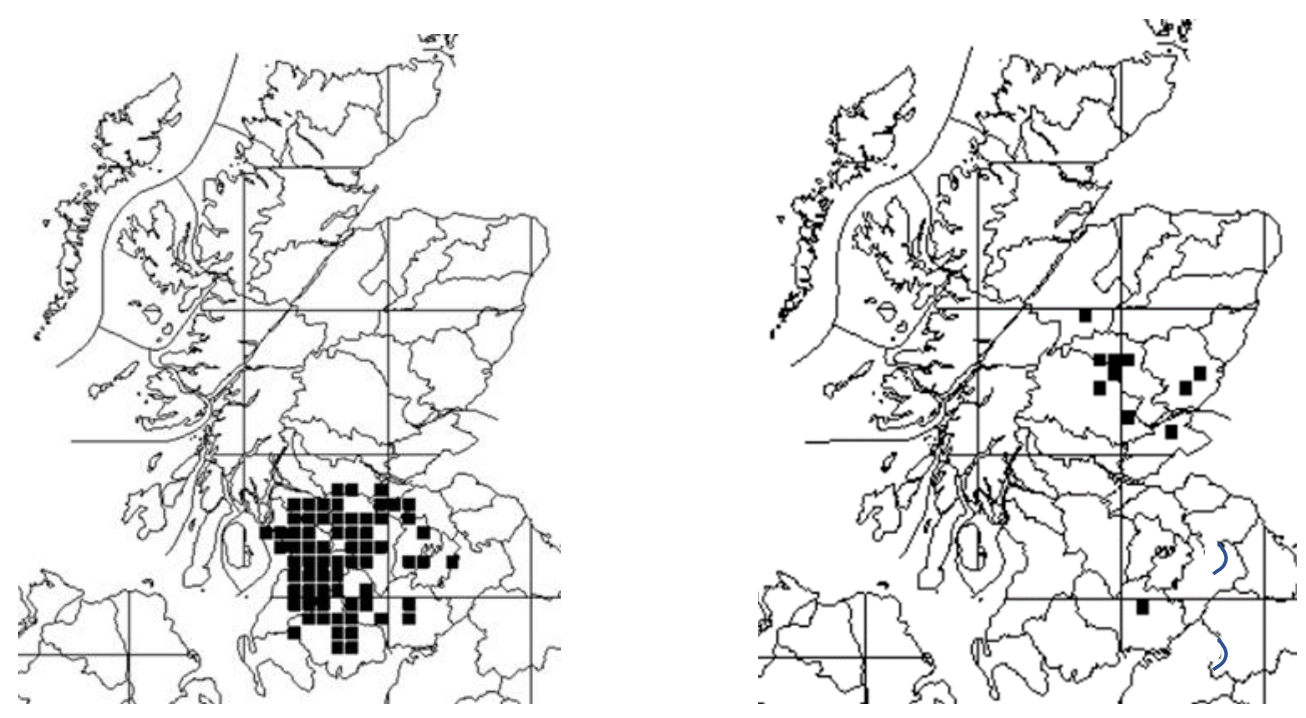

Fig. 4. Scottish records up to 2021 of Oedemera virescens (left) and O. lurida (right). Compiled by the author using MapMate.

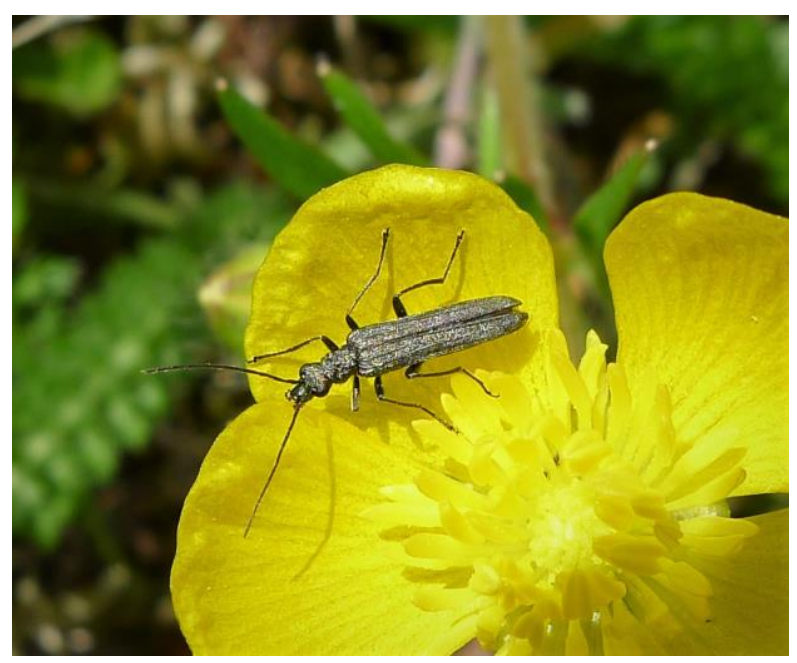

Fig. 5. Oedemera lurida. (Photo: (Ogailhampshire)

Perthshire. Since then, there have been several more records with the range being extended to Invernessshire, Angus, Fife and, with one recent record, Dumfriesshire (Steve Lane, pers. comm.) (Fig. 4). The very small number of confirmed records in central and southern Scotland is surprising as the species is relatively frequent in the north of England, and it seems likely that it must be more widespread than these records suggest. The similarity of both sexes of $O$. lurida to female $O$. virescens means that the verification of records is difficult, whereas $O$. virescens males can be easily confirmed from photos.

\section{DISCUSSION}

Of the five species of Oedemeridae that have been reliably recorded in Scotland only two - O. lurida and O. virescens - appear to be widespread. Surprisingly, there seems to be only a single record of either species until the 1990s. For species that are relatively large and conspicuous and which can readily be found in feeding in numbers on flowers such as buttercups this is surprising. It is unlikely that prolific recorders such as Sharp, Fergusson and Crowson could have overlooked them. It would therefore appear that there has been an increase in numbers and/or a significant range expansion. Possible explanations for this include land use changes, and climate-induced habitat factors but these have not been investigated for these species.

Because there are many records of Oedemera that cannot be attributed to a species ranging from the Scottish Borders to the Isle of Skye, the true extent of the ranges of the two species cannot be defined precisely. However, because $O$. virescens males are relatively easy to identify in the field, the Scottish distribution shown in Fig. 4 may be reasonably accurate. The situation regarding $O$. lurida is more complicated and more recording in the south of Scotland by experienced coleopterists may show it to be more widespread, although personal experience suggests that it is likely to be the less frequent species.

\section{ACKNOWLEDGEMENTS}

Many people have responded to the request for records and all are thanked for their efforts. Special thanks are due to Paul Cobb for sending in the most records and to Fraser Anderson for responding to a request well outside his comfort zone. Ashleigh Whiffin (National Museums Scotland), Jeanne Robinson (Hunterian Museum) and Richard Weddle (Glasgow Museums Biological Records Centre) kindly searched their collections for records while Richard Lyszkowski and Steve Lane provided some very useful information.

\section{REFERENCES}

Alexander, K.N.A., Dodds, S. \& Denton, J.S. (2014). A Review of the Scarce and Threatened Beetles of 
Great Britain. The Darkling Beetles and their Allies: Aderidae. Anthicidae, Colydiidae, Melandryidae, Meloidae, Mordellidae, Mycetophagidae, Mycteridae, Oedemeridae, Pyrochroidae, Pythidae, Ripiphoridae, Salpingidae, Scraptiidae, Tenebrionidae. Natural England Commissioned Report NECR148.

Beaumont, A. (1884). Captures of Coleoptera near Pitlochry, Perthshire. Entomologist's Monthly Magazine 20, 142.

Cathrine, C., Foster, G.N., Norris, G. \& Currie, N. (2020). Site Condition Monitoring of Beetle Assemblages at 11 Designated Sites in Scotland 2015. SNH Research Report No. 1115.

Crowson, R.A. (1964). Additional records of Coleoptera from Scottish oakwood sites. The Glasgow Naturalist 18(7), 371-375.

Duff, A.G. (2020). Beetles of Britain and Ireland. Volume 3: Geotrupidae to Scraptiidae. A.G. Duff, Norfolk.

Fergusson, A. (1914). Supplement to Dr. Sharp's "Coleoptera of Scotland". The Scottish Naturalist $25,40$.

Hyman, P.S. \& Parsons, M.S. (1992). A Review of the Scarce and Threatened Coleoptera of Great Britain. Part 1. JNCC.

Lane, S.A., Drewitt, A.L. \& Allen, A.J. (2019). IUCN Threat Status and British Rarity Status for British Coleoptera: Part 1. The Coleopterist 28, 71-100.

Morris, R. (1997). Oedemera virescens (Linnaeus) (Oedemeridae) in Scotland and North-east Yorkshire. The Coleopterist 5, 90.

National Biodiversity Network (2021a). NBN Atlas https://species.nbnatlas.org/species/NBNSYS00000 24935 Accessed June 2021.

National Biodiversity Network (2021b). NBN Atlas https://species.nbnatlas.org/species/NBNSYS00000 24943 Accessed June 2021.

National Biodiversity Network (2021c). NBN Atlas https://species.nbnatlas.org/species/NBNSYS00000 24942\# Accessed June 2021.

Philp, B. (2014). Oedemera virescens (Linnaeus) (Oedemeridae) in Scotland. The Coleopterist 23, 1720.

Sullivan, C. (2012). A few interesting records from Scotland. Beetle News 4.2, 4.

Vásquez, X.A. (2002). Fauna of European Oedemeridae. Argania Editio, Barcelona, Spain.

Waterston, A.R. (1935). A beetle Oncomera femorata (F.) new to the Scottish fauna. The Scottish Naturalist 1935, 98. 